\title{
Specify Additional Anesthesia
}

National Cancer Institute

\section{Source}

National Cancer Institute. Specify Additional Anesthesia. NCI Thesaurus. Code C159294.

A directive to specify additional anesthesia agents administered. 